\title{
(6) OPEN ACCESS \\ Fifty moves a year: is there an association between joint physical custody and psychosomatic problems in children?
}

\author{
Malin Bergström, ${ }^{1}$ Emma Fransson, ${ }^{1}$ Bitte Modin, ${ }^{1}$ Marie Berlin, ${ }^{2,3}$ Per A Gustafsson, ${ }^{4}$ \\ Anders Hjern ${ }^{1,5}$
}

${ }^{1}$ Centre for Health Equity Studies (CHESS), Stockholm University/Karolinska Institutet, Stockholm, Sweden

${ }^{2}$ National Board of Health and Welfare, Stockholm, Sweden ${ }^{3}$ Department of Sociology, Stockholm University, Stockholm, Sweden

${ }^{4}$ Department of Clinical and Experimental Medicine, Child and Adolescent Psychiatry, Linköping University, Linköping, Sweden

${ }^{5}$ Clinical Epidemiology, Department of Medicine Karolinska Institutet, Stockholm, Sweden

\section{Correspondence to}

Malin Bergström, Centre for Health Equity Studies (CHESS) Stockholm University/Karolinska Institutet, Stockholm 10691 , Sweden;

malin.bergstrom@ki.se

Received 14 October 2014 Revised 29 January 2015 Accepted 4 February 2015

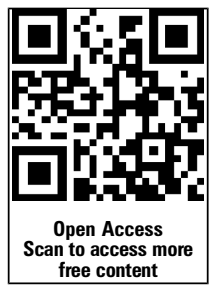

CrossMark

To cite: Bergström $\mathrm{M}$ Fransson E, Modin B, et al. J Epidemiol Community Health 2015:69:769-774.

\section{ABSTRACT \\ Background In many Western countries, an increasing} number of children with separated parents have joint physical custody, that is, live equally much in their parent's respective homes. In Sweden, joint physical custody is particularly common and concerns between $30 \%$ and $40 \%$ of the children with separated parents. It has been hypothesised that the frequent moves and lack of stability in parenting may be stressful for these children.

Methods We used data from a national classroom survey of all sixth and ninth grade students in Sweden $(\mathrm{N}=147839)$ to investigate the association between children's psychosomatic problems and living arrangements. Children in joint physical custody were compared with those living only or mostly with one parent and in nuclear families. We conducted sexspecific linear regression analyses for z-transformed sum scores of psychosomatic problems and adjusted for age, country of origin as well as children's satisfaction with material resources and relationships to parents.

Clustering by school was accounted for by using a twolevel random intercept model.

Results Children in joint physical custody suffered from less psychosomatic problems than those living mostly or only with one parent but reported more symptoms than those in nuclear families. Satisfaction with their material resources and parent-child relationships was associated with children's psychosomatic health but could not explain the differences between children in the different living arrangements.

Conclusions Children with non-cohabitant parents experience more psychosomatic problems than those in nuclear families. Those in joint physical custody do however report better psychosomatic health than children living mostly or only with one parent. Longitudinal studies with information on family factors before and after the separation are needed to inform policy of children's postseparation living arrangements.

\section{BACKGROUND}

During the past 20 years, it has become more common for children in the Western world to live alternatively and equally much with both parents after a parental separation. ${ }^{1-3}$ In Sweden, this practice of joint physical custody (JPC) is particularly frequent and has risen from about $1-2 \%$ in the mid-1980s to between $30 \%$ and $40 \%$ of the children with separated parents in $2010 .^{4}$ A possible reason behind the increase may be Sweden's active policy for parental equality. ${ }^{5}$ In 1974, Sweden, for example, was the first country to allow mothers and fathers to use paid parental leave, and since 1976 parents could continue having joint legal custody after a separation. The proportion of Swedish children born out of wedlock or to non-cohabiting parents is low compared with other Western countries. In 2009, the share was $6 \% .{ }^{4}$ Other assumed reasons behind the increase of JPC are women's participation in the labour force, ${ }^{5}$ which is very high in Sweden, ${ }^{6}$ and changes in Family Law facilitating JPC. ${ }^{8}$ The frequency of JPC in, for example, Belgium $^{9}$ and Australia ${ }^{10}$ has increased substantially after such legislative changes.

In international research, JPC has sometimes been defined as children living "at least one third of the time with each parent" 11 or included children whose parents have joint legal custody in this category. ${ }^{12}$ Joint legal custody, however, does not imply that the children necessarily live equal parts of the time with the two parents. In Sweden, JPC is so widespread that a more stringent categorisation $(50 / 50)$ is justifiable and has been applied in recent publications. ${ }^{13-15}$ In fact, the practice of JPC seems to constitute a new norm for separating Swedish parents, since $50 \%$ of recently split-up families report their children spending half the time in each parent's home. ${ }^{4}$ Furthermore, we have shown in a previous study that over $85 \%$ of all Swedish children aged 12-15 years live at least partly with both their parents, regardless of whether they are cohabiting or not. ${ }^{13}$ Despite the high frequency of JPC in Sweden, it is still possible that families with this arrangement vary in their socioeconomic characteristics from those with sole custody solutions. Results from a recent longitudinal study indicate that the more favourable socioeconomic situation that used to characterise JPC families no longer prevails as JPC has become more common, ${ }^{9}$ but other current research still suggests that parental health and well-being differ between parents with joint and sole care. ${ }^{16}$

Several studies over a long period of time have established that children with separated parents show higher risks for emotional problems and social maladjustment than those with cohabiting parents. ${ }^{17-19}$ One explanation for these increased risks may be the actual experience of the separation process and the emotional crisis possibly associated with this. Parental separation may also expose children to loss of social, economic and human capital. $^{4}{ }^{14}$ Other explanatory factors may derive from characteristics typical of separating parents such as lower relationship satisfaction and higher 
conflict levels also before the separation. ${ }^{4}$ The rising numbers of children with JPC have concerned child clinicians as well as researchers on the subject. ${ }^{20} 21$ Child experts have worried about children's potential feelings of alienation from living in two separate worlds, ${ }^{20-22}$ increased exposure to parental conflict $^{1222}$ and other stressors that JPC may impose on a child. ${ }^{22}$ Such daily stressors may be long distances to school, friends and leisure activities, lack of stability in parenting and home environment and a need to adjust to the demands of two different family lives. ${ }^{12} 22$ The logistics of travelling between their homes and keeping in contact with friends has been stated as a drawback of JPC in interview studies with children. ${ }^{23-25}$ Older adolescents, in particular, indicated that they preferred to be in one place. $^{23}$

The worries regarding children's well-being in JPC are enhanced by a simultaneous increase in children's psychological and emotional complaints and psychosomatic symptoms in Scandinavia. ${ }^{26} 27$ The higher frequency of such symptoms has been interpreted as a sign of increased stress in children's lives ${ }^{28}$ and could hypothetically also be related to stressors imposed by JPC. Already, stressful circumstances such as bullying, ${ }^{28}$ economic stress in the family, ${ }^{29}$ peer and teacher relationships, ${ }^{30} 31$ schoolwork pressure ${ }^{31}$ and lack of emotional support from the parents $^{32}$ have been shown to be related to psychosomatic symptoms in Swedish adolescents. However, even if the relationship between stress, psychological symptoms and psychosomatic problems is established, ${ }^{28}$ the mechanisms of how stress exposure and recurrent pain are associated are not fully understood. ${ }^{33}$

In this study, we wanted to investigate if the high frequencies of JPC and of psychosomatic problems in Swedish schoolchildren were related. We used a national sample of Swedish children aged 12 and 15 years to compare psychosomatic problems in children with JPC with those in nuclear families and living mostly and only with one parent. We also wanted to study the influence of two previously identified stressors: children's parental relations and material resources, on psychosomatic problems in relation to living arrangements.

\section{METHODS}

\section{Data source}

We used data from a national classroom survey, conducted in 2009, of psychosomatic symptoms in children aged 12 (grade 6) and 15 years (grade 9). The survey was conducted by Statistics Sweden under the mandate of the Swedish National Institute of Public Health. ${ }^{34}$ We were granted permission by the Swedish National Board of Health and Welfare to use the data. For the survey, 207700 pupils were eligible and 172391 (83\%) agreed to participate and were present in school when the survey was conducted. Of these, we included 147839 children who had completed the outcome instrument on psychosomatic problems and answered the questions on living arrangements, sex, age, country of birth and the items in the covariates 'parent-child relations' and 'material resources'.

\section{Outcome measures}

We used the PsychoSomatic Problems (PSP) scale as the outcome measure. This instrument includes eight items on psychosomatic problems in schoolchildren and adolescents. ${ }^{35}$ The eight questions concern the past 6 months and ask if the respondent had difficulties (1) concentrating (2) sleeping; suffered from (3) headaches (4) stomach aches; felt (5) tense, (6) sad (7) dizzy and had (8) little appetite. The response alternatives are never, seldom, sometimes, often and always.
Analyses of the dimensionality of the scale justify that the sums of scores are summarised across the items and transformed into a linear interval scale and have shown acceptable reliability and validity. ${ }^{35}$ Cronbach's $\alpha$ for the scale was 0.87 . Scores were transformed to z-values with a mean value of 0 and an SD of 1 for the multiple linear regression analyses. ${ }^{36}$ In table 2 , we also present proportions of children who reported that they 'often' or 'always' suffered from the respective problems (these response alternatives merged).

\section{Categorical variable}

Living arrangements were based on children's answers in the survey. The family arrangements were worded as follows: nuclear family; "always together with both mother and father", $J P C$; "approximately equally much with mother and father, for example one week with mother and the second week with father", mostly with one parent; "mostly with mother, sometimes with father" or "mostly with father, sometimes with mother" and only with one parent; "only with mother" or "only with father". We merged the gender-specific alternatives in the 'mostly' and 'only' categories since the numbers in the categories 'mostly' and 'only' with fathers were too small to allow for any meaningful statistical analyses.

\section{Covariates}

The covariates sex, age, children's and parent's country of origin were obtained from the questionnaire. Domicile was obtained from the National SIRIS database and categorised in accordance with a categorisation provided by the Swedish Association of Local Authorities and Regions. As potential mediators, we used sum scores of two subscales of subjective wellbeing from the KIDSCREEN-52 instrument: ${ }^{37}$ parent-child relations (six items, eg, Have you been able talk to your parent(s) when you wanted to?) and material resources (three items, eg, Have you had enough money to do the same things as your friends?). These scales were completed at the same time as the PSP scale and the questions concern experiences from the previous week with response alternatives assessing either intensity (not at all-slightly-moderately-very-extremely) or frequency (never-seldom-sometimes-often-always). High scores indicate more satisfaction. This instrument has shown acceptable reliability and validity. ${ }^{38}$ Cronbach's $\alpha$ for the parent-child relations scale was 0.91 and for the material resources scale 0.89 .

\section{Statistical analysis}

Linear multiple regression analyses, stratified by sex, were used to calculate $\beta$ coefficients on z-transformed sum scores of psychosomatic problems for the four living arrangements with JPC as a reference group. In model 1 , the confounders grade (6 vs 9) and country of origin (Swedish vs foreign born) are included. Model 2 includes the aforementioned confounders and continuous scores from the covariate 'material resources scale'. In model 3, the confounders and continuous scores from the covariate 'parents-child relations scale' are included. Finally, Model 4 is adjusted for all the aforementioned confounders and covariates. Clustering by school was accounted for by using a two-level random intercept model.

Interaction analyses demonstrated sex differences in psychosomatic symptoms in relation to all living arrangements, and we therefore decided to perform the analysis separately for girls and boys. There were no significant interaction effects for age and JPC. 


\section{RESULTS}

\section{Descriptive statistics}

As shown in table $1,69 \%$ of the 147839 children lived in nuclear families, $11 \%$ in JPC, $8 \%$ mostly with one parent and $13 \%$ only with one parent. The majority of those living mostly or only with one parent lived with their mother. About every sixth child in these arrangements lived with the father. Foreign born children had similar rates of separated parents as Swedish born children but JPC was more common for children with both parents born in Sweden (12\%) than if one $(10 \%)$ or both parents $(2 \%)$ were foreign born. There were small differences in living arrangements in relation to children's sex and domicile, but a larger proportion of the children aged 15 years lived with only one parent, compared with children aged 12 years. The differences were statistically significant at the $<0.001$ level.

\section{Psychosomatic problems}

As shown in table 2, children in nuclear families reported the least problems in terms of mean values on all items and total mean score. Children in JPC had slightly more problems, followed by those living mostly with one parent. Children who lived with only one parent reported most problems, in terms of mean scores, on all items. Also, the proportion of children who always or often suffered from different symptoms was highest among the latter group. These patterns were similar for girls and boys. For the sexes taken together, sleeping problems were most frequent: $22 \%$ among those living only with one parent, $19 \%$ living mostly with one parent, $14 \%$ in JPC and 13\% in nuclear families (sexes taken together). Also, suffering often or always from headaches was common: 19\% among those living with only one parent, $17 \%$ living mostly with one parent, $14 \%$ in JPC and $12 \%$ in nuclear families (sexes taken together).

Girls suffered from more problems than boys both when the PSP scale was analysed in terms of mean values and as a frequency of symptoms. Sadness was the most frequent problem for girls in all living arrangements, followed by sleeping problems and headaches. For boys, sleeping and concentration problems were most common. All these differences were statistically significant at the $<0.001$ level.

Standardised $\beta$ coefficients for psychosomatic problems in relation to living arrangements are presented in table 3 . They show that, compared with children in JPC, those living mostly or only with one parent report more psychosomatic problems than those in nuclear families. Adjusting for age and country of origin had practically no effect on the outcome, which is why the crude model is not presented. The $\beta$ estimates for children living mostly or only with one parent become weaker after adjustment for satisfaction with material resources (model 2) and parent-child relationships (model 3). Model 4 shows that both boys and girls who live mostly or only with one parent still have higher risks for psychosomatic problems than those in JPC, when all the aforementioned variables are included. Also, the lower risk for children in nuclear families, compared with JPC, remains through all the models.

Overall, girls report more psychosomatic problems than boys. Interaction analyses indicate interaction effects for psychosomatic problems and sex in all living arrangements. No differences for 12-year-old and 15-year-old children were found for the associations between JPC and psychosomatic symptoms.

\section{DISCUSSION}

In this cross-sectional study, based on a national survey of nearly 150000 Swedish children aged 12 and 15 years, children who live equally much with both parents after a parental separation suffered from less psychosomatic problems than those living mostly or only with one parent. Children in JPC, however, reported more psychosomatic problems than those in nuclear families, as did the children in the two other postseparation living arrangements. Our results show that children's satisfaction with their material resources and parent-child relationships affects children's psychosomatic health but cannot explain the differences between children in the different living arrangements.

Table 1 Characteristics of children by family type

\begin{tabular}{|c|c|c|c|c|c|c|c|c|}
\hline & \multicolumn{2}{|c|}{ Intact family } & \multicolumn{2}{|c|}{ Joint physical custody } & \multicolumn{2}{|c|}{ Mostly one parent } & \multicolumn{2}{|c|}{ Only one parent } \\
\hline & $\mathrm{N}$ & Per cent & $\mathbf{n}$ & Per cent & $\mathrm{n}$ & Per cent & $\mathrm{n}$ & Per cent \\
\hline Sample size & 101738 & 69 & 15633 & 11 & 11468 & 8 & 19000 & 13 \\
\hline Girls & 51003 & 68 & 7610 & 10 & 5916 & 8 & 10216 & 14 \\
\hline Boys & 50735 & 69 & 8023 & 11 & 5552 & 8 & 8784 & 12 \\
\hline \multicolumn{9}{|l|}{ Resident parent } \\
\hline Mother & & & & & 9455 & 82 & 15889 & 84 \\
\hline Father & & & & & 2013 & 18 & 3111 & 16 \\
\hline \multicolumn{9}{|l|}{ Age (years) } \\
\hline 12 & 48348 & 71 & 7655 & 11 & 4984 & 7 & 6855 & 10 \\
\hline 15 & 53390 & 67 & 7978 & 10 & 6484 & 8 & 12145 & 15 \\
\hline \multicolumn{9}{|l|}{ Location } \\
\hline Large city & 31224 & 68 & 5662 & 12 & 3167 & 7 & 6021 & 13 \\
\hline Small town & 49470 & 69 & 7663 & 11 & 5798 & 8 & 9054 & 13 \\
\hline Rural & 20938 & 70 & 2696 & 9 & 2495 & 8 & 3941 & 13 \\
\hline \multicolumn{9}{|c|}{ Children's national origin } \\
\hline Swedish & 93908 & 69 & 15319 & 11 & 10982 & 8 & 16507 & 12 \\
\hline Other & 7830 & 70 & 314 & 3 & 486 & 4 & 2493 & 22 \\
\hline \multicolumn{9}{|c|}{ Parents' national origin } \\
\hline Both Swedish & 75384 & 70 & 13220 & 12 & 8787 & 8 & 10689 & 10 \\
\hline One Swedish & 9957 & 58 & 1782 & 10 & 1669 & 10 & 3829 & 22 \\
\hline Neither Swedish & 15684 & 74 & 489 & 2 & 902 & 4 & 4098 & 19 \\
\hline
\end{tabular}


Table 2 Frequency of psychosomatic problems by gender and family type

\begin{tabular}{|c|c|c|c|c|c|c|c|c|}
\hline \multirow[b]{2}{*}{ Psychosomatic problems } & \multicolumn{2}{|c|}{ Nuclear family } & \multicolumn{2}{|c|}{ Joint physical custody } & \multicolumn{2}{|c|}{ Mostly with one parent } & \multicolumn{2}{|c|}{ Only with one parent } \\
\hline & Z/mean & Always/often & Z/mean & Always/often & Z/mean & Always/often & Z/mean & Always/often \\
\hline \multicolumn{9}{|l|}{ Girls N=74 745} \\
\hline Total score & 0.14 & NA & 0.33 & NA & 0.49 & NA & 0.53 & NA \\
\hline Concentration & 0.02 & 11 & 0.14 & 13 & 0.29 & 18 & 0.35 & 21 \\
\hline Sleeping & 0.06 & 16 & 0.17 & 18 & 0.30 & 23 & 0.36 & 26 \\
\hline Headaches & 0.13 & 16 & 0.23 & 18 & 0.38 & 23 & 0.43 & 25 \\
\hline Stomach aches & 0.17 & 12 & 0.30 & 14 & 0.42 & 18 & 0.48 & 21 \\
\hline Tense & 0.12 & 13 & 0.23 & 15 & 0.35 & 18 & 0.38 & 21 \\
\hline Little appetite & 0.11 & 11 & 0.24 & 13 & 0.38 & 18 & 0.44 & 21 \\
\hline Sad & 0.23 & 16 & 0.42 & 22 & 0.54 & 27 & 0.61 & 29 \\
\hline Dizzy & 0.06 & 11 & 0.18 & 13 & 0.32 & 18 & 0.40 & 21 \\
\hline \multicolumn{9}{|l|}{ Boys $n=73094$} \\
\hline Total score & -0.33 & NA & -0.21 & NA & -0.12 & NA & -0.10 & NA \\
\hline Concentration & -0.16 & 9 & -0.04 & 10 & 0.07 & 14 & 0.11 & 16 \\
\hline Sleeping & -0.18 & 10 & -0.11 & 11 & -0.01 & 15 & 0.04 & 17 \\
\hline Headaches & -0.25 & 8 & -0.16 & 9 & -0.08 & 10 & -0.05 & 12 \\
\hline Stomach aches & -0.29 & 5 & -0.22 & 5 & -0.16 & 6 & -0.14 & 7 \\
\hline Tense & -0.22 & 6 & -0.16 & 7 & -0.10 & 8 & -0.07 & 10 \\
\hline Little appetite & -0.23 & 5 & -0.17 & 6 & -0.11 & 7 & -0.06 & 8 \\
\hline Sad & -0.38 & 5 & -0.30 & 6 & -0.22 & 8 & -0.19 & 9 \\
\hline Dizzy & -0.19 & 6 & -0.11 & 7 & -0.02 & 9 & 0.01 & 10 \\
\hline
\end{tabular}

NA, not available.

Girls reported more psychosomatic problems than did boys while there were no age-related differences.

The pattern that children in JPC are in an intermediate position between children in nuclear families, having the least, and those in single care, having the most problems, is consistent with previous findings from our group as well as other research groups. This pattern has been established in relation to outcomes such as satisfaction with life, ${ }^{18}$ risk behaviour, ${ }^{15} 39$ parent-child relationships, ${ }^{11}$ school achievement, ${ }^{19}$ well-being ${ }^{13}$ and mental health. ${ }^{16}$

Table 3 Two-level random intercept linear regression model: standardised $\beta$ coefficients and $\mathrm{Cls}$ for psychosomatic symptoms in relation to living arrangements $(\mathrm{N}=147839)$

\begin{tabular}{|c|c|c|c|c|c|c|}
\hline & \multicolumn{2}{|c|}{ Nuclear families } & \multicolumn{2}{|c|}{$\begin{array}{l}\text { Mostly with one } \\
\text { parent }\end{array}$} & \multicolumn{2}{|c|}{$\begin{array}{l}\text { Only with one } \\
\text { parent }\end{array}$} \\
\hline & $\boldsymbol{\beta}$ & $\mathrm{Cl}$ & $\boldsymbol{\beta}$ & $\mathrm{Cl}$ & $\boldsymbol{\beta}$ & $\mathrm{Cl}$ \\
\hline \multicolumn{7}{|l|}{ Girls } \\
\hline Model 1 & -0.18 & -0.20 to -0.15 & 0.14 & 0.11 to 0.18 & 0.19 & 0.16 to 0.22 \\
\hline Model 2 & -0.11 & -0.14 to -0.09 & 0.09 & 0.06 to 0.12 & 0.10 & 0.07 to 0.13 \\
\hline Model 3 & -0.09 & -0.11 to -0.07 & 0.05 & 0.02 to 0.08 & 0.07 & 0.05 to 0.10 \\
\hline Model 4 & -0.07 & -0.09 to -0.05 & 0.04 & 0.01 to 0.07 & 0.05 & 0.02 to 0.08 \\
\hline \multicolumn{7}{|l|}{ Boys } \\
\hline Model 1 & -0.11 & -0.13 to -0.09 & 0.10 & 0.07 to 0.13 & 0.13 & 0.10 to 0.16 \\
\hline Model 2 & -0.08 & -0.10 to -0.06 & 0.06 & 0.03 to 0.09 & 0.06 & 0.03 to 0.09 \\
\hline Model 3 & -0.06 & -0.08 to -0.04 & 0.04 & 0.01 to 0.07 & 0.06 & 0.04 to 0.09 \\
\hline Model 4 & -0.05 & -0.06 to -0.03 & 0.03 & -0.00 to 0.05 & 0.03 & 0.01 to 0.06 \\
\hline \multicolumn{7}{|c|}{$\begin{array}{l}\text { Joint physical custody (equally much with both parents) serves as the reference } \\
\text { category. } \\
\text { Model } 1 \text { is adjusted for age and country of origin, model } 2 \text { is adjusted as model } 1 \\
\text { and for the child's perception of own material resources. Model } 3 \text { is adjusted as } \\
\text { model } 1 \text { and for the child's satisfaction with parents-child relations. Model } 4 \text { is } \\
\text { adjusted for all the previous variables. Clustering by school is accounted for by using } \\
\text { a two-level random intercept model. }\end{array}$} \\
\hline
\end{tabular}

Psychosomatic symptoms are related to stress, ${ }^{28}$ but despite the fact that two homes require adaptation to different neighbourhoods and family climates, our results show lower risks for psychosomatic symptoms for children in JPC than in single care residency. This result confirms findings from more previous small-scale studies. For example, Turunen ${ }^{40}$ as well as Carlsund et $a l^{14}$ found lower risks of stress in JPC than in single residency after controlling for family and child characteristics as well as parent-child relationships. Also, an American study showed that children in JPC had fewer stress-related illnesses and health problems than those living only with their mothers. ${ }^{1}$ Taken together, this indicates that the potential stress from living in two homes could be outweighed by the positive effects of close contact with both parents. Although children in interviews have brought up hassles of JPC, ${ }^{23-25}$ most children also state that close relationships with both their parents are more important. $^{25} 41$

It is, however, possible that the difference in psychosomatic health between children in nuclear families and JPC may, at least partly, be explained by family factors associated with the parents' separation or divorce. Separated parents more often have psychological problems and poor economy than co-living parents and may have had relationship problems and conflicts also before the separation. ${ }^{4}{ }^{42}$ Such factors directly affect children's psychological health and symptom load ${ }^{143}$ and could be important for how families arrange custody and children's housing after the split-up. ${ }^{19}$ In this study, children living with only one parent reported the least satisfaction with their relationships to their parents, followed by those living mostly with one parent. Children with JPC were slightly less satisfied with their parent relations than those in nuclear families. This pattern is in line with previous publications on children's parental relations in different living arrangements. ${ }^{4} 42$

Adding indicators of parent-child relationships and material resources to models $2-4$ in the regression analyses lowered the 
associations between psychosomatic problems and living arrangements considerably. These findings are consistent with previous studies that have demonstrated a mediating effect of parent-child relationships and material resources on the relationship between psychosomatic health and living arrangements. ${ }^{31} 4445$ Positive relationships to parents have been found to be more common in children in JPC than in single care, in particular to the fathers. ${ }^{13} 3246$ Children's satisfaction with their material resources was included as a potential mediator since economic stress has previously been shown to be associated with psychosomatic symptoms in children ${ }^{29}$ and is more common among children with separated parents. ${ }^{4}{ }^{13}$ Also, these conditions reduced the differences in psychosomatic health between the living arrangements.

Girls in JPC reported more psychosomatic problems than boys, as did girls living mostly or only with one parent. The pattern of psychosomatic problems in relation to living arrangements was, however, similar for both sexes. Since girls generally report more psychosomatic ill health than boys, ${ }^{26} 27$ the sex differences in relation to living arrangements may possibly be explained by our outcome variable rather than an actual worse situation for girls after a parental separation. Earlier studies have reached varying results regarding gender differences after parental separations. ${ }^{47}$ In a previous study, we found no differences for boys and girls on the effects of JPC on well-being. ${ }^{13}$ Further studies are thus needed to reveal if JPC and other postseparation arrangements have a different impact on boys and girls.

\section{Methodological issues}

We had the advantage of using a national survey with a validated outcome measure on psychosomatic problems. ${ }^{35}$ The large sample size allows us to draw conclusions on the entire population of Swedish children aged 12 and 15 years. This is a considerable strength since previous studies have had high rates of attrition ${ }^{12}$ or suffered from small sample sizes, preventing, for example, comparisons between JPC and single care. ${ }^{14}$

The national sample also ensures inclusion of families with different background characteristics. In her reviews, Nielsen ${ }^{11}$ argues that JPC families today have less social, economic and relationship advantages compared with single care families, but there is still a risk that families with different postseparation arrangements differ in ways that affect children's psychosomatic health. In Sweden, it is estimated that around 14\% of separating parents have conflicts regarding custody and children's housing ${ }^{4}$ and about $2 \%$ have their custody disputes resolved in court. ${ }^{49}$

Despite the strength on a total population sample, our data are limited regarding contextual variables that may affect children's health. We included measures on children's material resources and parent relationships but lack other types of information on the families' socioeconomic situation and the level of parents' cooperation or conflict. Children's reports of satisfaction with these aspects may possibly reflect their own personalities and coping strategies rather than the actual strain on the family. The lack of objective data on the families' situations is an important limitation since such factors are associated both with children's living arrangements and directly with their psychosomatic health. ${ }^{18} 5051$

Another limitation is the lack of information on when the children had experienced the parental separation. Ideally, the results of this study should be confirmed by studies with a longitudinal design and access to information on psychological as well as socioeconomic family factors.

Finally, we consider our categorisation of JPC as a strength. In the survey, the alternative JPC was worded "approximately equally much with mother and father, for example one week with mother and the second week with father", which indicates that the JPC category actually includes children who spend $50 \%$ of their time with each of the parents. Nearly $8 \%$ of the participants choose the category "living mostly with one parent", which implies that children's actual housing after a parental separation is not entirely black or white with respect to everyday contact with the parents. Our categorisation thus gives a more nuanced picture than studies where only the single care and JPC categories are included, ${ }^{39}$ where JPC includes children living $30 \%$ or less with one parent ${ }^{111}$ or where the JPC category even includes families with joint legal custody but primary residency with one parent. ${ }^{12}$

\section{Implications}

Children who share their time between the parent's respective homes after a separation experience less psychosomatic problems than those living mostly or only with one parent. Their satisfaction with their material resources and parent-child relationships is important for their psychosomatic health but cannot explain the differences between children in different living arrangements. Longitudinal studies with information on family factors before and after the separation are needed to inform policy of children's postseparation living arrangements.

\section{What is already known on this subject?}

The practice of joint physical custody, that is, children spending equal time in the respective homes of their separated parents, has become more frequent in Western countries over the past decade. At the same time, there has been an increase in self-reported paediatric psychosomatic symptoms. Child health experts have argued that joint physical custody imposes stress on children.

\section{What this study adds?}

In a Swedish national sample of children aged 12 and 15years, we found that children in joint physical custody suffered from less psychosomatic problems than those living mostly or only with one parent but reported more symptoms than did those in nuclear families.

Acknowledgements The authors thank the Swedish National Board of Health and Welfare for granting them permission to use the data.

Contributors MBe conceived the study, participated in the design and drafted the manuscript. BM provided expertise regarding the data source, interpretation of the data and the statistical analysis. EF participated in the design of the study and interpretation of the data. MB provided expertise regarding demography and the data source and participated in the interpretation of the data. PAG provided expertise regarding child psychiatry and participated in the interpretation of the data. $\mathrm{AH}$ participated in the design of the study, provided expertise regarding the data source, performed the statistical analyses and interpretation of the data and helped to draft the manuscript. All authors read and approved the final manuscript.

Funding This study was funded by Länsförsäkringsbolagens Forskningsfond. Competing interests None.

Ethics approval Karolinska Institute, Stockholm, Sweden.

Provenance and peer review Not commissioned; externally peer reviewed. 
Open Access This is an Open Access article distributed in accordance with the Creative Commons Attribution Non Commercial (CC BY-NC 4.0) license, which permits others to distribute, remix, adapt, build upon this work non-commercially, and license their derivative works on different terms, provided the original work is properly cited and the use is non-commercial. See: http://creativecommons.org/ licenses/by-nc/4.0/

\section{REFERENCES}

1 Melli M, Brown PR. Exploring a new family form - the shared time family. Int J Law Policy Fam 2008;22:231-69.

2 Spruijt E, Duindam V. Joint physical custody in The Netherlands and the well-being of children. J Divorce Remarriage 2010;51:65-82.

3 Heide Ottosen M. Samvaer og borns trivsel [Joint custody and children's well-being]. Copenhagen, Denmark: Social Studies Institute, 2004.

4 Swedish board of health and welfare. Family law and the child in custody disputes (in Swedish). Stockholm, Sweden, 2011.

5 Juby HLBC, Marcil-Gratton N. Sharing roles, sharing custody? Couples' characteristics and children's living arrangements at separation. J Marriage Fam 2005;67:157-72.

6 Sundström M. Managing work and children: part-time work and the family cycle of Swedish women. In: Blossfeld HP, Hakim C. eds. Between equalization and marginalization. Women working part-time in Europe and the United States of America. Oxford: Oxford University Press, 1997:272-88.

7 Fehlberg B, Smyth B, Maclean M, et al. Legislating for shared time parenting after separation: a research review. Int J Law Policy Fam 2011:25:318-37.

8 Fehlberg B, Smyth B, Mclean M, \& Roberts C \& University of Oxford. Dept. of Social Policy and Social Intervention (2011). Caring for children after parental separation: would legislation for shared parenting time help children? University of Oxford, Dept. of Social Policy and Intervention, Oxford.

9 Sodermans AK, Matthijs K, Swicegood G. Characteristics of joint physical custody families in Flanders. Demogr Res 2013;28:821-48.

10 Kaspiew R. Cashmore J. Parkinson P, et al. Shared care parenting arrangements since the 2006 Family Law Reforms: report to the Australian Government Attorney-General's Department. University of New South Wales. Social Policy Research Centre, 2010:18-52.

11 Nielsen L. Shared residential custody: review of the research (part II of II). Am J Fam Law 2013;27:61-71.

12 Bauserman R. Child adjustment in joint-custody versus sole-custody arrangements: a meta-analytic review. J Fam Psychol 2002;16:91-102.

13 Bergström $\mathrm{M}$, Modin B, Fransson $\mathrm{E}$, et al. Living in two homes-a Swedish national survey of wellbeing in 12 and 15-year-olds with joint physical custody. BMC Public Health 2013;13:868.

14 Carlsund $\AA$, Eriksson U, Sellström E. Shared physical custody after family split-up: implications for health and well-being in Swedish schoolchildren. Acta Paediatr 2012;102:318-23.

15 Jablonska B, Lindberg L. Risk behaviours, victimisation and mental distress among adolescents in different family structures. Soc Psychiatry Psychiatr Epidemiol 2007;42:656-63.

16 Bergström M, Fransson, E, Hjern, A, et al. Mental health in Swedish children living in joint physical custody and their parents' life satisfaction: a cross-sectional study. Scand J Psychol 2014;55:433-9.

17 Amato PR, Soblowski JM. The effects of divorce and marital discord on adult children's psychological well-being. Am Sociol Rev 2001;66:900-21.

18 Bjarnason T, Bendtsen $\mathrm{P}$, Arnarsson $\mathrm{A}$, et al. Life satisfaction among children in different family structures: a comparative study of 36 western societies. Child Soc 2012:26:51-62.

19 Breivik K, Olweus D. Adolescent's adjustment in four post-divorce family structures. J Divorce Remarriage 2006;44:99-124.

20 Mclntosh J, Smyth B, Wells Y, et al. Post-separation parenting arrangements and developmental outcomes for infants and children. Collected reports. Victoria, Australia: Australian Institute of Family Studies, 2010.

21 Warshak RA. Social science and parenting plans for young children: a consensus report. Psychol Public Policy Law 2014;20:46-67.

22 Gilmore $S$. Contact/shared residence and child well-being: research evidence and its implications for legal decision-making. Int J Law Policy Fam 2006;20:344-65.

23 Cashmore J, Parkinson, P, Weston R, et al. Shared care parenting arrangements since the 2006 Family Law Reforms: report to the Australian Government
Attorney-General's Department. Social Policy Research Centre. University of New South Wales, 2010.

24 Haugen GMD. Children's perspectives on everyday experiences of shared residence: time, emotions and agency dilemmas. Child Soc 2010;24:112-22.

25 Smart C, Neale B, Wade A. The changing experience of childhood: families and divorce. Malden, MA: Blackwell Publishers, 2001.

26 Danielsson M. Skolbarns hälsovanor (The Swedish version of the WHO HSBC study]. Stockholm, Sweden: The Swedish Public Health Institute, 2003

27 Karvonen S, Vikat A, Rimpela M. The role of school context in the increase in young people's health complaints in Finland. J Adolesc 2005;28:1-16.

28 Alfvén G, Östberg V, Hjern A. Stressor, perceived stress and recurrent pain in Swedish schoolchildren. J Psychosom Res 2008;65:381-7.

29 Östberg V, Alfvén G, Hjern A. Living conditions and psychosomatic complaints in Swedish schoolchildren. Acta Paediatr 2006;95:929-93.

30 Bergh D, Hagqvist C, Starrin B. Social relations in school and psychosomatic health among Swedish adolescents - the role of academic orientation. Eur J Public Health 2010:21:699-704.

31 Hjern A, Alfvén G, Östberg V. School stressors, psychological complaints and psychosomatic pain. Acta Paediatr 2008;97:112-17.

32 Låftman S, Bergström M, Modin B, et al. Joint physical custody, parental emotional support and subjective health: a large-scale study of adolescents in Stockholm, Sweden. Scand J Public Health 2014;42:456-62.

33 McEwan B. Physiology and neurobiology of stress and adaptation: central role of the brain. Physiol Rev 2007;87:873-904.

34 The Swedish Public Health Institute. Survey of mental health among school children. http://www.fhi.se/en/Publications/Summaries/Survey-of-mental-health-amongchildren-and-adolescents. Secondary Survey of mental health among school children 2011. http://www.fhi.se/en/Publications/Summaries/Survey-of-mental-health-amongchildren-and-adolescents

35 Hagquist C. Psychometric properties of the PsychoSomatic Problems scale: a Rasch analysis on adolescent data. Soc Indicators Res 2008;86:511-23.

36 Cohen J. Statistical power analysis for behavioral sciences. Hillsdale: Lawrence Erlbaum Associates, 1988.

37 The KIDSCREEN Group Europe. The KIDSCREEN Questionnaires. Handbook Lengerich, Germany: Pabst Science Publishers, 2006.

38 Ravens-Sieberer U, Gosch A, Rajmil L, et al. The quality of life measure for children and adolescents: psychometric results from a cross-cultural survey in 13 European countries. Value Health 2008;11:645-58

39 Carlsund A, Eriksson U, Löfstedt $\mathrm{P}$, et al. Risk behaviour in Swedish adolescents: is shared physical custody after divorce a risk or a protective factor? Eur J Public Health 2013:23:3-8.

40 Turunen J. Shared physical custody and children's experience of stress. Annual Meeting of the Population Association of America. New Orleans, USA: The Population Association of America, 2013.

41 Skjørten K, Barlindhaug R, Lidén H. Delt bosted for barn. Oslo: Gyldendal akademisk, 2007

42 Gähler M. Life after divorce. Stockholm University, 1998.

43 Amato PR. Children's adjustment to divorce: theories, hypotheses and empirical support. J Marriage Fam 1993;55:23-38.

44 Due $\mathrm{P}$, Lynch J, Holstein B, et al. Socioeconomic health inequalities among a nationally representative sample of Danish adolescents: the role of different types of social relations. J Epidemiol Community Health 2003;57:692-8.

45 Fabricius W, Luecken L. Postdivorce living arrangements, parent conflict, and longterm physical health correlates for children of divorce. J Fam Psychol 2007:21:195-205.

46 Bjarnason T, Arnarsson Arsaell M. Joint physical custody and communication with parents: a cross-national study of children in 36 western countries. J Comp Fam Stud 2011;42:871-91.

47 Nielsen L. Divorced Fathers and Their Daughters: A Review of Recent Research. J Divorce Remarriage 2011;52:77-93.

48 Spruijt EDV. Problem behavior of boys and young men after parental divorce in the Netherlands. J Divorce Remarriage 2005;43:141-56.

49 Rejmer A. Vårdnadstvister. En rättssociologisk studie av tingsrätts funktion vid handläggning av vårdnadstvister med utgångspunkt från barnets bästa. (In Swedish). Lunds Universitet, 2003.

50 Kelly JB, Emery RE. Children's adjustment following divorce: risk and resilience perspectives. Fam Relations 2003;52:352-62.

51 Lansford JE. Parental divorce and children's adjustment. Perspect Psychol Sci 2009;4:140-52. 